Sicherheit geheilt werden, wenn allo im Blute vorhandenen Stoffe dem Körper, und zwar in resorbirbarer Form zugefthrt werden. Verf. ist es nach langer, vergeblicher Arbeit gelungen, ein haltbares, in heissem Wasser wie auch in alkoholhaltigen Flüssigkeiten leicht lösliches Pulver herzustellen, welches sämmtliche im Blute vorhandenen Salze und Eiweissstoffe enthält - also Hämoglobulin nebst Hämatin, sowie Serumalbumin und Paraglobulin (mit Ausnahme von Fibrin). Es sind mit diesem Pulver bis jetzt relativ wenige. Versuche (seit vier Wochen) gemacht worden, jedoch ist eine auffallend günstige Wirkung bei Chlorose und allgemeiner Schwäche ausnahmslos eingetreten. Im hiesigen städtischen Krankenhause nahm bei dem ersten Versuch eine seit sechs Monaten behandelte Patientin in 14 Tagen drei Pfund zu (Dosis funfmal täglich $1 \mathrm{~g}$ ). Bei einer anderen Patientin konnte in 14 Tagen funf Pfund Zunahme constatirt werden (Dosis dreimal täglich $1 \mathrm{~g}$ ) etc. Ueberall trat schnell Appetit ein bei vor allem gebesserter Gemüthsstimmung.

Das Pulver, dem Verf. des uberwiegenden Eiweissgehaltes wegen den Namen Hämalbumin geben möchte, enthält die Eiweissarten als saure nicht coagulirbare Albuminate, die auch von einem Organismus resorbirt werden können, dessen Magen keine verdauungsfähigen Säfte secernirt. Das Hämalbumin wird von der chemischen Fabrik F. W. Klever, Köln a. Rh. hergestellt. Der Preis ist nur halb so hoch wie der des Liquor Ferri albuminati, dieser als vierprocentige Lösung aufgefasst. Verf. möchte nicht unterlassen, zu erwähnen, dass Calcium- und Magnesium-Di- und Triphosphat von dem Hämalbumin in lösliche Eiweissverbindungen übergeführt werden, und dürfte die gute Wirkung derselben bei Rhachitis ausser Zweifel stehen.

\title{
Ueber Hämalbumin, ein neues diätetisches Präparat und seine Wirkung bei Chlorose.
}

Von Dr. Max Dahmen in Crefeld.

Im allgemeinen werden Eisenpräparate als Specifica gegen Chlorose betrachtet. Sehr oft jedoch ist die Darreichung von Eisen ohne jeden Erfolg. Dies legt den Gedanken nahe, ob diese Krankheit des Blutes nicht a ch durch Mangel anderer für ein gesundes Blut nothwendiger Stoffe hervorgerufen werden kann. Es müsste alsdann die Chlorose mit absoluter 